\title{
DIGNIDAD SOCIAL Y AUTORIDAD. EL LEGADO DE ROMA Y SU PRESENCIA EN EL PROTOCOLO DE NUESTROS DÍAS
}

\section{Luis Rodríguez Ennes}

Professor catedrático de Direito Romano

Universidad de Vigo, Espanha.

Sumário: Introducción. II.- Evolución histórica: 1.- Roma imperial; 2.- Edad Media; 3.- Edad Moderna: A) Introducción del "Uso de Borgoña" por Carlos I; B) Luis XIV y los Borbones españoles; C) La Galicia del Antiguo Régimen.

\section{INTRODUCCIÓN}

A lo largo del devenir histórico, la prioridad jerárquica, leit motiv del protocolo, se ha erigido en un proceloso campo de disputas. Con mayor o menor énfasis - pero sin excepción- desde los remotos tiempos faraónicos, hasta la era de la moderna cibernética, las civilizaciones se han preocupado de las delicadas materias protocolarias y ceremoniales. En todo tiempo y lugar se fue arbitrando un compendio de normas para armonizar la representación de los distintos estamentos sociales; de ahí que alguien apuntase-con notorio acierto- que la ciencia y el arte del protocolo constituyen una mezcla inseparable entre la tradición del pasado y la complejidad del presente, marcado éste por el mayor sentido práctico y utilitario que preside la vida moderna ${ }^{1}$. De acuerdo con esta premisa inicial, mi trabajo se circunscribirá a un recorrido por la evolución de las normas protocolarias, comenzando por la mejor documentada y más influyente civilización de la Antigüedad -la romana- y concluyendo con el actual marco normativo. Con ello trato de demostrar una vez más la razón que encierra el aforismo clásico: historia est magistra vitae.

\section{II - Evolución Histórica}

\section{ROMA IMPERIAL}

El emperador poseía la más alta dignitas en la sociedad romana y no sólo en virtud del poder que le confería la constitución, sino también merced a su posición personal2: podía en todo momento apelar a la auctoritas de su persona,

${ }^{1}$ Cfr. PUMAR VÁZQUEZ, Cerimonial e protocolo (Vigo, 1995) p. 9.

2 ALFÖLDY, Historia social de Roma, trad. esp. Alonso Troncoso (Madrid, 1987) p. 139. 
de la que Augusto afirmaba que ya únicamente por ella "podía considerarse superior al resto de los hombres"3, añadiéndose a ésto que al soberano se le tenía por la encarnación ideal de todas las virtudes romanas. Su autoridad sin parangón se expresaba en una titulación imperial paulatinamente formalizada (Imperator Caesar Augustus) con recuento de los distintos tipos de poder y dignidades ${ }^{4}$, en su atuendo e insignias especiales, y en el ceremonial que rodeaba a su persona, reforzado todo ello por su carisma religioso, que el culto al Emperador -y en el oriente grecoparlante- la divinización mantenían constante ${ }^{5}$.

El cambio fundamental experimentado por el sistema político romano con la introducción de la monarquía imperial afectó a las funciones públicas de los grupos situados en la cúspide de la sociedad, es decir a los integrantes de los estamentos senatorial y ecuestre, cuyos servicios - en la época republicana prestados al Estado- se van a considerar a partir de ahora como ofrecidos al emperador ${ }^{6}$.

Los "mejores" por razón de privilegios escritos y no escritos, eran tratados con especial respeto tanto por parte de los estratos inferiores, como también por el propio Estado. Según una disposición de Vespasiano, un senador no podía ser ofendido ni siquiera por un caballero y, caso de ser éste el agraviado, quedaba autorizado a lo sumo a devolver la ofensa por mediación de un miembro del primer orden, ya que la dignitas que se le reconocía al primero y al segundo de los órdenes no era la misma ${ }^{7}$. Las personas distinguidas eran objeto

\footnotetext{
${ }^{3}$ Auctoritate ómnibus praestiti, cfr. Res Gestae Divi Augusti, 34.

4 Entre las mayores preocupaciones de Augusto destaca la relativa a que su nombre reflejase la posición de supremacía que había alcanzado. Para ello prescindió sucesivamente, del nomen y praenomen de Cayo Octavio y de los derivados de su adopción testamentaria por César, C. Julio, y únicamente conservó el cognomen adoptivo de Caesar (en cierto modo transformado en nombre) y el de Augusto que le otorgara el Senado. A ellos antepuesto, como si fuera un praenomen, el título de imperator y se hizo llamar Imperator Caesar Augustus; palabras que terminaron siendo consideradas por sus sucesores, no como nombres personales, sino cual sinónimos de princeps [Cfr. ARANGIO RUIZ, Historia del Derecho Romano ${ }^{3}$, trad. esp. Pelsmaeker (Madrid, 1975) p. 274].

5 Acerca de la posición del príncipe, vid.: Recherches sur l'aspect idéologique du principat (Basilia, 1953); WICKERT, en RE, XXII (1954), col. 1998 ss., y en ANRW, II, 1 (Berlín-Nueva York, 1974) p. 3 ss. Sobre la auctoritas: MAGDELAIN, Auctoritas Principis (París, 1947). Culto imperial, insignias y ceremonias: TAEGER, Carisma. Estudien zur Geschichte des antiken Herrscherkultes, II (Stuttgart, 1960); ALFÖLDY, Die monarchische Repräsentation im römischen Kaiserreiche (Darmstadt, 1970); bibliografía en HERZ, ANRW, II, 16,2 (Berlín-Nueva York, 1978) p. 833 ss.

${ }^{6}$ Sobre Augusto y las capas altas de la sociedad: SYME, Roman Revolution (Oxford, 1939) p. 276 ss.

7 SUETONIO, Vesp. 9, 2. Con todo, el segundo orden -el ecuestre- también se caracterizaba por su etos aristocrático y no profesional. A juicio del historiador DIÓN CASIO $(52,19,4)$, el orden ecuestre se parecía al senatorial en que para ingresar en él había que responder a los mismos criterios -noble linaje, excelencia y riqueza-, pero en el segundo grado. Al igual que los senadores, los ecuestres fueron objeto de intentos de imponer respetabilidad moral a fuerza de leyes, como el senatus consultum del año 19 d. C. que prohibió a los miembros de ambos órdenes y a sus familias que se deshonraran actuando en espectáculos públicos; [el decreto sanatorial está recogido en D. 23, 2, 4 pr., cfr. al repecto: TREGGIARI, Roman freedmen during the Late Republic (Oxford, 1964) p. 82 ss ; LEVICK, "The Senatus Consultum from Larinum", en JRS 73 (1983) p. 97-115].
} 
de particular reverencia por la masa ${ }^{8}$ y gozaban de especiales prerrogativas en materia de derecho penal: los componentes del estamento ecuestre que cometían actos delictivos por los que una persona corriente se vería condenada a trabajos forzados, habían tan sólo de marchar al exilio; los senadores culpables de un crimen capital estaban libres de la pena de muerte y debían únicamente ir al destierro9. El resto de los mortales, por el contrario, quedaba sujeto a todas las severidades del ordenamiento punitivo romano ${ }^{10}$.

Los senadores tenían derecho al título de clarissimus y sus mujeres e hijas al de claríssima, lucían como insignias de su estamento la franja ancha de púrpura en la túnica o latus clavus ${ }^{11}$, frente a los caballeros que llevaban una franja estrecha o angustus clavus y ostentaban además el título de eques Romanus ${ }^{12}$. Con todo, en época augústea, el orden senatorial siguió siendo el más prestigioso, un reducido círculo formado por varios centenares de familias a las que se consideraba eminentes de acuerdo con las tradicionales pautas de cuna, riqueza y excelencia moral. Augusto se propuso reconstruir el senado y reavivar su moral hundida purgándolo de miembros de categoría dudosa que se habían infiltrado en el orden senatorial durante las guerras civiles -una serie de revisiones hicieron que el número de senadores bajara de unos 1-200 a 600- y acentuando las diferencias entre senadores y hombres de rango inferior ${ }^{13}$. El orden senatorial no era, en modo alguno, una aristocracia hereditaria. Pese a ello, el prestigio que se atribuía a la noble alcurnia empujó a Augusto a promover el principio hereditario con el fin de elevar la categoría del senado, permitiendo a los hijos de los senadores asistir a las reuniones del senado con sus padres ${ }^{14} \mathrm{y}$ haciendo extensiva la distinción senatorial

8 TÁCITO, Ann. 3, 23.

${ }^{9}$ Cfr. FERRINI, Diritto penale romano, ed. anast (Roma, 1976) p. 143 ss.

10 Para MOMMSEN, así como las desigualdades legales en la aplicación de la pena a los libres y a los no libres eran tan antiguas como la misma Roma, las desigualdades legales en la aplicación de la pena a los nobles y a los simples ciudadanos se remontan a los tiempos de Augusto y Tiberio, supuesto que el primero de estos emperadores abolió la igualdad de derecho, que había sido el producto de la secular lucha de clases, mediante la creación de la nueva nobleza hereditaria y la nueva nobleza personal; y el segundo dio forma y expresión en el orden penal a la antítesis entre ciudadanos de clase superior y ciudadanos de clase inferior, mandando que los trabajos forzados sólo pudieran imponerse a estos últimos y no a los primeros. Pero el sistema así implantado no llegó a adquirir firmeza y desarrollo completos hasta las generaciones posteriores, las disposiciones de Marco Aurelio acerca de la aplicación del tormento fueron las que contribuyeron de una manera esencial a establecer una separación marcada entre las dos categorías de personas a las que nos referimos. [Cfr. Derecho Penal Romano, trad. esp. Dorado Montero (Bogoyá, 1976) p. 641].

11 CHASTAGNOL, "Les modes d'accés au sénat romain au debut de l'empire", en Bull. Soc. Antiq. France (1971) p. 283-310; 1D.; "La naissance de l'orde senatorius", en MEFR 85 (1973) p. 583-607.

12 MILLAR, A study of Caessius Dio (Oxford, 1964) p. 21, ID, "Empire and city, Augustus to Julian: obligations, excuses and status", en JRS 83 (1983) p. 1-23; PFLAUM, "Titulature et rang social sous le haut-empire", en Nicolet (ed.) Recherches sur les estructures sociales dans l'antiquité classique (París, 1970).

13 GARNSEY-SALLEER, El Imperio Romano: economía, sociedad y cultura, trad. esp. J. Beltrán (Barcelona, 1990) p. 135.

14 SUETONIO, Aug. 38. 
a los descendientes de los senadores durante tres generaciones ${ }^{15}$, y se ofrecieron incentivos al orden senatorial para que se reprodujera ${ }^{16}$. Empero, al finalizar el principado, el ecuestre principal, el prefecto pretoriano, ya procedía a los senadores en el protocolo de la corte. Los romanos, que eran gente consciente del rango, no querían que el inmenso abismo social que había entre el ecuestre más encumbrado y el más humilde pasara desapercibido, de modo que a finales del siglo II se inventó una nueva jerarquía de epítetos para designar a los ecuestres que ocuparan cargos (egregius o "excelente" para los procuradores; perfectissimus o "perfectísimo" para los prefectos de mayor categoría, y eminentissimus o "eminentísimo", para los prefectos pretorianos ${ }^{17}$.

Los romanos hacían alarde de su rango siempre que aparecían en público, y en ninguna parte lo hacían de forma tan conspicua como en los espectáculos que se daban en el teatro, el anfiteatro y el circo. En Roma, Augusto confirmó y extendió las disposiciones de finales de la república que reservaban asientos o filas de asientos para los senadores, los ecuestres y los ciudadanos ${ }^{18}$. En los municipios, los asientos se disponían de forma que dieran definición especial a la distinción entre el orden curial y los ciudadanos corrientes. La ley que promulgara César para la colonia de Urso -actual Osuna- en Hispania, ya había dado instrucciones claras sobre la disposición de los asientos en el anfiteatro y el teatro, a la vez que establecía multas enormes para las infracciones, lo cual indica que estaba en juego algo más que obtener una buena localidad ${ }^{19}$.

La última ley municipal romana descubierta ${ }^{20}$, conocida como Lex Irnitana, también confirma esta disposición en su capítulo $81^{21}$. Poner a cada quien en su sitio apropiado era afirmar de modo visible la dominación de la estructura social imperial, y tenía por fin impresionar al grueso de la población del imperio.

\footnotetext{
D. 23, 2, 44 pr.

16 HOPKINS, Death and renewal (Cambridge, 1983), sobre las leyes referentes al matrimonio en p. 143 ss.

17 MILLAR, $A$ study, cit., p. 21; PFLAUM, "Titulature" cit.

18 No nos resistimos a transcribir, por su vis descriptiva, lo que constata SUETONIO al respecto: "Promulgó reglas especiales para impedir el sistema desordenado y fortuito que usaban los espectadores para obtener asientos en estos espectáculos, habiéndose indignado al saber del insulto recibido por un senador, a quien al entrar en el abarrotado teatro de Puteoli, ningún miembro del público le ofreció un asiento. El consiguiente senatus consultum dispuso que en todas las funciones, dondequiera que se celebrasen, la primera fila de la platea debía reservarse para los senadores... Otras reglas suyas incluían la separación de los soldados de los civiles; la asignación de asientos especiales para los plebeyos casados, para los muchachos que aún no fueran mayores de edad y, cerca de ellos, para sus tutores; y la prohibición de vestir prendas oscuras, excepto en las últimas filas" (Cfr. Aug. 44). Se refieren también a estos hechos: DIÓN CASIO, 60, 7 ; SUETONIO, Claud., 21; TÁCITO, Ann., 15, 32.

19 RICCOBONO, Fira I, 21 (Lex col. Gen. Iul. Urs.) p. 125-127, especificando una multa de 5.000 sestercios.

20 El hallazgo de estas tablas de bronce - todas menos una rotas en varios fragmentos- tuvo lugar, en una búsqueda irregular, en la primavera de 1981, en la colina llamada Molino del Postero, a $5 \mathrm{kms}$. al SW de El Saucejo y $3 \mathrm{kms}$. al NE de Algámitas, en la provincia de Sevilla. La primera edición crítica se debe a JULIÁN GONZÁLEZ, y fue publicada en Journal of Roman Studies (JRS) 76 (1986) p. 147-238.

21 Cfr. D’ORS, Lex Irnitana (texto bilingüe) (Santiago de Compostela, 1988) p. 64.
} 
El carácter despótico de la monarquía romana se hizo más evidente en la época bajo imperial. Los emperadores eran tenidos por "soberanos de la tierra bajo el sol y señores victoriosos"22, por "señores de todas las cosas humanas" el trato con ellos quedó marcado en adelante por un rígido ceremonial de corte, fuertemente influido por modelos orientales; la desobediencia al soberano no sólo se consideró como un acto criminal sino como un sacrilegio. La concepción que tenían del emperador paganos y cristianos se diferenciaba en que para los primeros el soberano seguía apareciéndoseles como un Dios (p. ej. Paneg. 12, 4, 5), mientras que los segundos veían en él a un monarca por la gracia de Dios; pero ésto no cambiaba en nada el carácter sacral de su persona, como tampoco la infinita distancia entre soberano y súbdito, pues el emperador era también en la visión cristiana el elegido por la summa divinitas, a quien ésta "confiaba el gobierno de todo lo terrenal"24.

Diocleciano -arquetipo del monarca absoluto tardorromanogustaba de lo solemne. El acceso a su persona se hizo cada vez más difícil a causa del creciente ceremonial. En las salas y vestíbulos del palacio había colocados oficiales, cortesanos y guardias; en el interior mandaban eunucos influyentes; quien por el asunto y el rango, podían llegar hasta el emperador, tenía que prosternarse a la manera orienta ${ }^{25}$. Diocleciano tenía viejos amigos, pero la confianza había desaparecido, acaso por ambos lados; temía, y no sin razón, que su intimidad con terceras personas podía perturbar su artificial armonía con los colegas. En lugar de la simple púrpura con que se habían contentado casi todos los emperadores anteriores -excepción hecha de los dementes- viste (desde 293) ropajes de seda recamados y salpica sus sandalias de piedras preciosas y perlas; ciñe su cabeza con la diadema, una cinta blanca cubierta de perlas. Este era el uniforme oficial en que se presentaba en las ocasiones solemnes. Con motivo del encuentro de Diocleciano y Maximiano en Milán -291- el panegirista Mamertino ${ }^{26}$ describe la solemne corte como una "adoración escondida en lo más íntimo del santuario, que había de asombrar únicamente los ánimos de aquellos a los que su rango les permitiera llegar hasta vos". Y no quedaban las cosas en formalismos mudos, pues también se pronunció la palabra escabrosa; el emperador ya no se nombraba según los títulos - tan inocuos entonces- de la Roma republicana: el cónsul, el poder tribunicio, etc., se llamaba dominus, el señor ${ }^{27}$.

${ }^{22}$ Inscriptiones Latinae Selectae (ILS) 8809.

${ }^{23}$ Ibid. 807.

${ }^{24}$ Opt. Milev., App. 3. Idea del emperador en el Bajo Imperio: STRAUB, Von Herrscherideal in der Spätantike ${ }^{3}$ (Stuttgart, 1964); ALFÖLDY, Die monarchische Repräsentation im römischen Kaiserreiche (Darmstad, 1970).

${ }^{25}$ BUCKHARDT, Del paganismo al cristianismo. La época de Constantino El Grande, trad. esp. E Imaz (Madrid, 1982) p. 46.

${ }^{26}$ Paneg., III. 11.

27 En el tratamiento acostumbrado al emperador este título aparece de vez en cuando en inscripciones de Valeriano, Galerio y Aureliano. 
No sabemos si en la corte de Diocleciano el lenguaje no era todavía algo más servil y mezclado con frases de adoración. En todo caso, el ceremonial, por lo que se refiere a la persona imperial, debió ser aún un poco inocente y no muy alambicado; de seguro que no se le puede comparar con la corte bizantina, en la que en el siglo X, el emperador Constantino Porfirogeneta ${ }^{28}$ actuó en persona de maestro de ceremonias de la corte para conducir con un hilo sistemático a los contemporáneos y a la posteridad a través de aquel laberinto de prácticas sagradas, cuyo carácter servil se va impmoniendo poco a poco a los autócratas sacrosantos y divinos desde que se entrelazan y exaltan recíprocamente el ceremonial eclesiástico y el cortesano ${ }^{29}$.

Sí, del trono para abajo, el régimen de títulos y rangos se fue apoderando poco a poco de la sociedad romana, no hay que achacarlo sin más a Diocleciano. El proceso natural de anquilosamiento de la vida antigua tenía que adoptar inevitablemente esta forma. Hacía largo tiempo que el gobierno venía siendo casi por completo un gobierno de soldados; ahora bien, un régimen semejante conformará siempre todo el aparato estatal a su imagen y semejanza, es decir, con un orden riguroso y visible de grados y dignidades, porque su alma es la subordinación. Muchas disposiciones externas de este tipo que se suelen atribuir a Diocleciano, posiblemente se presentaron ya antes, pero la transformación definitiva de la vida estatal tuvo lugar bajo Constantino ${ }^{30}$.

Y es que, justamente con el llamado "primer emperador cristiano", se asiste a un perfeccionamiento del ceremonial y de los oficios de palacio. La llamada Notitia Dignitatum, un calendario de la corte y del estado de principios del siglo $\mathrm{V}^{31}$, enumera una jerarquía completa de los cargos palatinos y estatales que es posible que, en general haya cobrado forma de manos de Constantino, aunque es cosa que tampoco se puede demostrar directamente. De las diversas

28 El papel histórico de Constantino Porfirogeneta, no está en su insignificante actividad como hombre de Estado -sólo reinó entre 945-959- sino en su trabajo extremadamente intensivo y fecundo en el campo de la cultura y de la ciencia. Compuso una enciclopedia bajo el título de Libro de las ceremonias -a la que nos referimos en el nt. 29- de incalculable valor como fuente histórica; también redactó una disertación histórico-gráfica sobre las provincias del Imperio, un tratado importantísimo sobre países y pueblos y una biografía de su abuelo Basilio I. Varias obras históricas notables, así como una serie de diversos escritos científicos y tratados prácticos nacieron por orden o iniciativa suya; también fomentó con gran entusiasmo la recopilación de resúmenes tomados de antiguos escritores, sobre todo de los historiadores. El escritor y mecenas portador de corona dio un impulso poderoso a las fuerzas espirituales del Imperio, suscitando una actividad científica sin par. [Cfr OSTROGORSKY, Historia del Estado Bizantino, trad. esp. J. Facci (Madrid, 1983) p. 279-280].

29 El enorme Libro de las Ceremonias (De caerimoniis aulae byzantinae), representa una verdadera mina de información histórica y arqueológica.[Existe una edición francesa con comentario de VOGT, Le livre des Cérémonies (París, 1935, 1939-1940) del libro I, caps. 1-83]. Una de las fuentes más importantes de esta obra la constituye el Klerologion de Filoteo, que nos informa sobre la jerarquía de los funcionarios alrededor de 900. [Edición separada con un excelente comentario de BURY, The Imperial Administrative System in the Ninth Century (Londres, 1911)].

${ }^{30}$ BUCKHARDT, Del paganismo al cristianismo, cit., p. 57-58.

${ }^{31}$ Existe una edición de la Notitia Dignitatum, a cargo de SEECK (Berlín, 1876) que es la que hemos manejado. 
dignidades sabemos que muchas de ellas existían ya bajo Diocleciano y aún mucho antes desde Adriano. De todos modos la tabla - por lo mismo que no se conocen estos antecedentes- tiene algo de sorprendente ya que revela la fastuosidad del despotismo. Por todas partes resuena el adjetivo sacer (sagrado) cuando bastaba con decir "imperial". Y en qué forma el mundo romano de entonces se acostumbró al sistema de títulos como símbolos de una jerarquía nos lo dicen los tratamientos corrientes de illuster, spectabilis, honoratus, clarissimus, perfectissimus, egregius, etc. ${ }^{32}$. Por otra parte, los privilegios de los cortesanos, manejados consecuentemente y ampliados, tenían que producir poco a poco una nueva nobleza hereditaria germen, a su vez, del feudalismo.

\section{EdAD MEDia}

En la Europa altomedieval se había extendido la idea -formulada por un reducido número de intelectuales- de que el mundo estaba concebido de tal manera que cada uno tenía sus misiones específicas atribuidas por Dios desde la Creación ${ }^{33}$. La función principal -en teoría que no en la práctica- la desempeñaban los hombres dedicados a rezar por las almas de todos -oratores- los bellatores [verdadero grupo dominante de la época ${ }^{34}$ ] debían consagrar su vida a la defensa y protección del conjunto social; y, por último, los laboratores desempeñaban la necesaria - pero menos considerada- función de trabajar para el mantenimiento de los otros grupos. Era un esquema simple de justificación de las desigualdades existentes que se estableció firmemente en la mentalidad colectiva de la época y que perdurará durante varios siglos, configurando la llamada "sociedad de los tres órdenes" ${ }^{\prime 3}$.

Por otra parte, los teóricos políticos del absolutismo monárquico, concebían la sociedad civil como la transposición del orden celestial ${ }^{36}$. Aceptada la desigualdad como componente natural y fundamental de ese orden, se adaptaron las teorías de los antiguos para formular una concepción más ligada alas ideas cristianas La idea de la igualdad había sido ya tomada por los Padres de la Iglesia de Cicerón y Séneca. San Gregorio Magno había enseñado ya a la naciente Edad

32 Los datos accesibles de la Notitia, entre otros en KÖRTUM, Römische Geschichte, p. 412 ss.; FIEDLER, Römische Geschichte, en los apéndices.

33 GARCÍA HERNÁN, La nobleza en la España moderna (Madrid, 1992) p. 12.

${ }^{34}$ DUBY, Guerreros y campesinos. Desarrollo inicial de la economía europea (500-1200) (Madrid, 1976) p. 208.

35 Así, en 1539, en las Epistolas familiares de ANTONIO DE GUEVARA, famoso Obispo mindoniense y, a la sazón, confesor de Carlos I, podemos leer: "En la buena república el sacerdote ora, el labrador ara y el caballero pelea" (Cfr. Ep. III).

36 Se contempla un orden celestial que contenía la sociedad de ángeles repartidos en nueve coros, a su vez clasificados en tres órdenes o jerarquías. La más alta de éstas, la de los tres coros de serafines, querubines y tronos, representará a la nobleza del cielo. [Cfr. BENNASAR, La España del Siglo de Oro (Barcelona, 1983) p. 39]. 
Media el Omnes namque homines natura aequales sumus ("Todos los hombres somos iguales por naturaleza"). Esta sentencia había sido repetida con los más diversos acentos y matices ${ }^{37}$, sin aminorar la afectiva desigualdad; pues para el hombre medieval, el punto céntrico de la idea estaba en la cercana igualdad ante la muerte, no en una inasequiblemente lejana igualdad ante la vida. En Eustache Descamps la encontramos en claro enlace con la idea de la danza de la muerte ${ }^{38}$, que era para la última Edad Media asolada por la Peste Negra ${ }^{39}$, un consuelo de la injusticia del mundo ${ }^{40}$. Tal apelación a la muerte como único ras igualatorio expresada en el popular aforismo latino sic transit gloria mundi- va a permanecer viva durante todo el Antiguo Régimen, como lo demuestran sin género de dudas, tanto los autos sacramentales de nuestro Siglo de Oro como las macabras obras pictóricas de Peter Brueghel, el Bosco o el sevillano Valdés Leal.

Pese a las iras de algunos intelectuales que clamaban contra la injusticia social y el atentado a la más pura moral cristiana que suponía la desigualdad $^{41}$, lo cierto era que estaba generalmente admitida la idea de la necesidad de un buen orden y armonía dentro de la sociedad y de la obligatoriedad de la

37 La unión de la idea de igualdad con la de la nobleza de corazón halla certera expresión en las palabras de Ghismonda a su padre Tancredo, en el primer cuento del cuarto día, en el Decamerón boccacciano.

38 Según DESCHAMPS, Es Adán quien habla así a su descendencia: "Hijos míos, hijos míos, de mí, Adán nacidos/ Que soy, después de Dios, el padre primero/ Creado por Él, todos de mí habéis descendido/ Según naturaleza, de mi costilla y de Eva/ Ella es vuestra madre ¿Cómo es el uno villano/Y el otro toma de gentilhombre el título/ Entre vosotros, hermanos ¿de dónde/procede semejante nobleza?/Yo no lo sé, a menos que sea de las virtudes/Y de todo vicio que hiere, los villanos/ Todos estáis de la misma piel revestidos- vous estes tuos d'une pel revestus-“ [Cfr. Oeuvres complétes, ed. De Queus-Raynaud (París, 1878-1903) VI, núm. 1.140, p. 67].

39 La Peste Negra fue la gran plaga de una Edad Media abundante en enfermedades epidémicas. Surgió en la colonia genovesa de Caifa (Crimea), asediada por un ejército mongol que contrajo la enfermedad y la contagió a los sitiados. Transmitida por marinos genoveses, la peste alcanzó a Constantinopla y en 1347 a Italia. Al año siguiente se había propagado a Francia y a los territorios de la Corona de Aragón. En 1349 se extendió a Inglaterra y en 1350 azotaba a los reinos ibéricos occidentales. Al transmitirse también hacia el valle del Danubio y Escandinavia, llegó un momento en que toda Europa y el Próximo Oriente padecían los efectos de la enfermedad. El gran azote de la Peste Negra en sus diversas formas -bubónica, pulmonar o septicémina- tuvo así carácter general a mitad del siglo XIV, y de ella se hizo eco BOCACCIO en la introducción al Decamerón. En los años siguientes hubo otras oleadas de la enfermedad, de alcance más restringido. [Cfr. VALDEÓN, "La muerte negra en la Península y "El impacto de la peste", en Historia 16, 56 (1980) p. 60-66 a 71, respectivamente].

40 Los misioneros venían de tiempo en tiempo para sacudir al pueblo con su voz. Nosotros, lectores de periódicos, apenas podemos imaginarnos el poderosos efecto de la palabra hablada sobre un espíritu ignorante. El hermano Ricardo, predicador popular, predicó en París en 1429, durante diez días sucesivos. Hablaba desde las cinco hasta las diez o las once de la mañana en el cementerio de los Inocentes, bajo cuya galería estaba pintada la célebre "Danza de la muerte", de espaldas a las fosas comunes, en las cuales yacían amontonados y rebasando de la arcada los cráneos, a la vista del público [Cfr. HUIZINGA, El Otoño de la Edad Media, trad. esp. José Gaos (Madrid, 2001), p. 17].

${ }_{41}$ Por ejemplo A. LÓPEZ DE VEGA, que en su Heráclito y Demócrito de nuestro siglo Diálogos morales sobre tres materias, la nobleza, la riqueza y las letras (Madrid, 1641), dentro del tono filosófico y moral de toda la obra, denuncia -en boca de su personaje Heráclito- la tremenda injusticia de la desigualdad como principio contrario a la naturaleza humana y al propio cristianismo, se dirigen casi siempre, en tono velado e irónico, contra los hidalgos (a quienes 
existencia de una minoría dirigente que garantizara ese deseable equilibrio y que permitiera el desarrollo de un buen gobierno. Además, los propios contemporáneos eran muy conscientes de que la desigualdad conllevaba inevitablemente el afán por la superación personal, que es "lo bueno para el buen orden de la República ${ }^{42}$. La general aceptación - al menos para la vida terrena- de tamaña desigualdad, implicaba la existencia de hecho y de derecho de miembros de la sociedad con atributos de superioridad sobre la masa de "hombres del común"43. Así pues, existía una estructuración jerárquica dentro de la sociedad y una minoría de privilegiados que se elevaba en múltiples aspectos sobre los que no gozaban de tales prerrogativas. Privilegio es palabra clave para comprender el concepto de superioridad social de la nobleza, así como para definir el denominador común -casi único- que hace de este grupo social un conjunto de miembros con una cierta homogeneidad.

Tal sociedad es también llamada sociedad de órdenes o de estados, que se caracteriza fundamentalmente porque configura un modelo social jerarquizado, basado en la desigualdad, en diferentes estratos o estamentos compartimentalizados, pero no rigurosamente cerrados, que confieren unos determinados privilegios y obligaciones para sus miembros de acuerdo con la consideración social y, más explícitamente, con la específica reglamentación jurídica que tienen asignada ${ }^{44}$. El concepto de "estado" no sólo tiene más valor, sino también una significación mucho más amplia. En general, se considera un estado toda agrupación, toda función, toda profesión, hasta el punto de haber podido existir junto a la división de la sociedad otra división en doce ${ }^{45}$. La idea de la organización de la sociedad en "estados" penetra, pues, en la Edad Media todas las especulaciones teológicas y políticas hasta sus últimas fibras; no se limita, en absoluto, a la consabida trinidad: clero, nobleza y tercer estado.

Así las cosas, estát y ordre abrazan en el medievo un gran número de agrupaciones humanas que son muy heterogéneas para nuestro modo de pensar: los estados en el sentido de nuestras clases sociales, el estado de matrimonio junto al estado de soltería, el estado de pecado -etát de pechié-, los cuatro estáts de corpe et de bouche -estados de la boca y del cuerpo- de la corte: panetiers, escanciadores, trinchantes y maestros de cocina; las órdenes

42 Biblioteca Nacional, ms. 2364, fol. 88-93.

43 La definición de nobleza que daría GUARDIOLA, en su Tratado de nobleza y de los títulos y ditados que oi día tienen los varones y grandes de España (Madrid, 1591), es muy interesante a este respecto:”... es una calidad... mediante la qual se demuestra accepto y agradable. Más que todos los honestos plebeyos".

44 MORALES MOYA, en Poder politico, economía e ideología en el siglo XVIII español: La posición de la nobleza (Madrid, 1983) p. 714-721, nos proporciona un clarificador y, en nuestra opinión, acertado análisis sobre la consideración de la nobleza española como estamento y como clase. P. CHAUNU, por su parte, afirma: 'La nobleza n'est pas une classe au sens strict, mais les divisions au sein de la noblesse sont des divissions de classe" [Cfr. "La societé espagnole au XVIIe siécle. Sur un refus collectif de mobilité”, en Bulletin Hispanique 78 (1966) no 1-2, p. 104-115].

45 POLLARD, The Evolution of Parliament (Londres, 1920) p. 58 ss. 
sacerdotales -presbítero, diácono, subdiácono, etc.-, las órdenes monásticas, las órdenes militares ${ }^{46}$. Lo que para el pensamiento medieval confiere unidad al concepto de "estado" o de "orden" en todos estos casos, es la creencia de que cada uno de estos grupos representa una institución divina, es un órgano de la arquitectura del universo, tan esencial y tan jerárquicamente respetable como los Tronos y las Dominaciones celestiales de la jerarquía angélica ${ }^{47}$.

\section{Edad Moderna}

Tampoco puede sorprendernos que, de acuerdo con estas premisas, el tratamiento y el ceremonial, al llevar consigo la constatación externa de la pertenencia a un determinado status, fuera cuestión fundamental en el Antiguo Régimen. La observancia puntillosa de estos modos de encasillar a las personas de acuerdo con su rango, que a nosotros nos puede parecer ridícula, era una realidad social tan importante época que daba origen en muchas ocasiones a innumerables pendencias y disputas por el uso indebido de "vuesa merced" o su "ilustrísima", o una reverencia a destiempo. El ceremonial -según las estrictas normas de la etiqueta -obviamente se hacía más ostensible y riguroso en la Corte, donde cada uno tenía perfectamente asignados su dignidad y su puesto ${ }^{48}$.

Como ha apuntado el ilustre sociólogo Salustiano del Campo ${ }^{49}$ : realeza significa magnificencia, excelencia, generosidad. Rodeada de pompa, esplendor y ceremonia, la persona del rey se convierte en símbolo y simboliza. En símbolo polivalente con funcionalidad múltiple y con plurales radiaciones expresivas. Corporeiza de forma visible un síndrome moral, un principio aglutinador abstracto. Era rey y representaba a cada uno de los reinos. Es una imagen -la real- centralizadora y estabilizante que fusiona la sociedad fragmentada.

La divinización de la realeza austríaca puede apreciarse mejor si observamos al rey a los cortesanos en acción ritual en el palacio, en la apoteosis del rey. El protocolo, la etiqueta, el comportamiento formal y solemne reconoce y activa la sociedad encarnada en el cuerpo resplandeciente del monarca; el protocolo riguroso y la ceremonia escenifican y reproducen cotidianamente, en cada acto oficial, su deificación, el menos por analogía. El modo de conducirse el rey, sus

${ }^{46}$ HUIZINGA, El Otoño, cit. p. 77.

47 Vid., la nt. 36

48 Un curioso ejemplo de entre los múltiples que podríamos consignar: como los grandes no se podían cubrir en el interior del cuarto real o en la audiencia particular que el rey les diera, Don Francisco de Melo, gobernador de Flandes, que tenía la pretensión de ser grande de España, siempre que lo necesitó pidió hablar con el rey (para no sufrir el "despecho" de tener que cubrirse donde los grandes no lo hacían) en audiencia en la Galería (en lo más interno de las habitaciones reales; sólo dos estancias antes de donde se viste el monarca. [Cfr. CARRILLO, Origen de la dignidad de grande de Castilla, preeminencias de que gozan en los actos públicos, y palacio de los Reyes de España (Madrid, 1657) fol. 33].

49 SALUSTIANO DEL CAMPO, Contestación al discurso de ingreso de C. Lisón Tolosana en la Real Academia de Ciencias Morales y Políticas (Madrid, 1992) p. 217. 
vestidos y manera de hablar, su estilo, su encubrimiento, su distanciamiento y compostura, le hacen diferente, le colocan aparte, separado, y a ello ayudan las cortinas, las alfombras, los baldoquines, los estrados y el trono, todos los cuales -juntamente con los tabúes que le rodean- transmiten la idea de un tesoro en un relicario, conforman una imagen única de poder místico y esencia deífica ${ }^{50}$.

\section{A) Introducción al "uso de Borgoña" por Carlos I.}

La corte es el lugar donde con más plenitud pueden desplegarse las formas estéticas de la vida. Es sabido cuánta importancia concedían los duques de Borgoña a todo lo que se refería al esplendor y brillo cortesanos. Después de la gloria guerrera, dice Chastellain ${ }^{51}$, es el brillo de la corte lo primero en que se pone la mira y cuya regulación y buen orden son de suma necesidad. Olivier de la Marche, el maestre de ceremonias de Carlos el Temerario -bisabuelo de nuestro Carlos I- escribió, a requerimientos del rey Eduardo VI de Inglaterra, su tratado sobre la brillantez de la corte ducal borgoñesa, recomendando al rey inglés que imitase aquel modelo de vida ceremoniosa y de etiqueta ${ }^{52}$. De Borgoña heredaron los Habsburgo la vida de corte pomposa y elegante y la trasplantaron a España y Austria, cuyas cortes han sido sus baluartes hasta el primer tercio del siglo XX. La corte de Borgoña era universalmente celebrada como la más rica y mejor ordenada de todas.

Principalmente, Carlos el Temerario, un hombre imbuido del más estricto espíritu de disciplina y regularidad y que, sin embargo, no dejó tras de sí más que desorden, tenía una verdadera pasión por la vida sometida a reglas fijas de protocolo. Dos o tres veces por semana daba, después de la comida, una audiencia pública, en la cual cualquiera podía acercársele y exponer sus peticiones. Todos los nobles de la casa debían estar presentes y ninguno osaba faltar. Separados cuidadosamente según su rango, permanecían sentados a ambos lados del paso libre que conducía a la elevada silla del duque. Arrodillados a sus pies estaban los dos maitres de requestes, el audiencier y un secretario, que leían los memoriales y los despachaban como quería el príncipe. Detrás de unas balaustradas que rodeaban la sala, permanecía en pie el personal inferior de la corte. Era por su aspecto -dice Chastellain ${ }^{53}$-une chose magnifique et de grand los ("algo magnífico y digno de alabanza").

Las ordenanzas relativas a la ordenación jerárquica de la corte son de una exhuberancia rabelesiana, cuando tratan de las comidas y d ela cocina. La mesa de Carlos el Temerario con todos sus servidores -panetiers,

${ }^{50}$ Ibid, p. 217-218.

${ }^{51}$ CHASTELLAIN, Oeuvres, (ed. Kervyn de Lettenhove) ocho volúmenes, Bruselas, 1883-1866, V, p. 364.

52 OLIVIER DE LA MARCHE, Mémoires (ed. Beaune et d'Arbaumont), cuatro volúmenes, París, 18831888, IV, p. CXIV.

53 CHASTELLAIN, Oeuvres, cit., V, p. 370. 
trinchantes, escanciadores, mestres de cocina, cuyas funciones estaban reguladas con una severidad casi litúrgica, semejaba la representación de un grande y grave espectáculo. La corte entera comía en grupos de diez, en cubículos separados, servidos y atendidos como el señor, todo cuidadosamente ordenado conforme al rango y la clase. La Marche plantea a sus lectores importantes cuestiones de jerarquía y de etiqueta: "Por qué los panetiers y los escanciadores ocupan, respectivamente, el primero y segundo rangos, por encima de los trinchantes y de los cocineros? Porque sus cargos se refieren al pan y al vino, cosas santas glorificadas por la dignidad del sacramento ${ }^{54}$. Como se ve, existe una efectiva relación entre la esfera de la fe y la de la etiqueta cortesana. No cabe insistir bastante en que aquel aparato de exquisitas y nobles formas de vida alberga un elemento litúrgico que ha elevado el valor de las mismas a una esfera cuasi religiosa.

Sólo este elemento puede explicar la extraordinaria importancia que, más allá de la última Edad Media se ha concedido siempre a todas las cuestiones de jerarquía y ceremonial. No tiene, pues, nada de extraño que en el antiguo imperio ruso, antes de los Romanov, la lucha por un lugar precedente cabe al trono condujese a la creación de un departamento concreto de la Administración del Estado. Las monarquías occidentales del medievo no llegaron tan lejos, pero también en ellas representa un gran papel la envidia causada por dicha precedencia. Fácil sería amontonar los ejemplos.

En orden a las penas, los hidalgos estaban exentos de sufrir las corporales infamantes, entendiendo por tales no la pena de infamia propiamente dicha, sino aquellas que la doctrina llamaba corporis afflitiva (azotes, galeras, vergüenza pública, mutilaciones...), y que por su naturaleza provocaban en el así penado una disminución o pérdida de su pública fama ${ }^{55}$. Tampoco se les podía imponer la pena de muerte en su forma de ejecución tenida por más vil o deshonrosa, que era la de horca. Excluidas estas penas, sólo quedaban como posibles para aplicar a los nobles las pecuniarias, presidios, destierro, la de servir en el ejército real y la muerte en forma no vil. Así las cosas, incluso en el cadalso eran observados rigurosamente los honores debidos al rango y a la clase. Las ejecuciones de los nobles se efectuaban con pompa. El cadalso se cubría con paños negros y se encendían hachas y blandones, el entierro del cadáver se hacía solemnemente ${ }^{56}$. No obstante, y por lo que respecta a España, hubo notables y aún altos personajes que fueron ejecutados e inhumados tan austera y pobremente como

54 OLIVIER DE LA MARCHE, Etat de la maison du duc Charles de Bourgogne (ed. Matthaeus), en Analecta I, p. 357 ss.

55 Vid, al respecto, TOMÁS Y VALIENTE, El Derecho penal de la monarquía absoluta ${ }^{2}$ (Madrid, 1992) p. 319 ss.

56 El patíbulo del connétable de Saint Pol está ricamente adornado con lirios marchitos; el almohadón para orar y el paño para los ojos son de terciopelo carmesí, y el verdugo es un individuo que no ha ejecutado nunca a nadie, privilegio algo dudoso para el condenado. [Cfr. MOLINET, Chronique, ed. Buchon (París, 1827-28) 5 vols. I, p. 184)]. 
los más pobres malhechores ${ }^{57}$.Con todo, lo normal, en la inmensa mayoría de los casos, fue que el noble fuese castigado con destierro y pena pecuniaria o a lo sumo a servir cierto número de campañas en un ejército del rey ${ }^{58}$. COVARRUBIAS, por no citar más que a un autor en una cuestión en la que están todos de acuerdo, resume la opinión de los doctores italianos e indica que la pena corporal no se puede imponer a los nobles, y que atendiendo a la cualidad de las personas es justísimo cambiar para los nobles las penas corporales en pecuniarias o de destierro ${ }^{59}$.

Goethe escribió: "No hay ningún signo externo de cortesía que no tenga una profunda razón de ser moral". El sentimiento del honor es tan fuerte que una falta contra la etiqueta hiere como una ofensa moral -lo mismo que aún hoy en muchos pueblos orientales- porque echa por los suelos la bella ilusión de una vida propia elevada y pura, ilusión que sucumbe siempre ante la desnuda realidad. Es para Juan Sin Miedo causa de una vergüenza inextinguible el que Capeluche, el verdugo de París, que con gran pompa se cruza a caballo con él, le haya saludado como si fuera un simple caballero y haya rozado su mano; solamente la muerte del verdugo puede borrar esta afrenta. En el banquete de gala que se da el día de la coronación de Anjou, reclamando el puesto que le correspondía como doyen des pairs. Sus respectivos séquitos intervienen el punto con voces y amenazas con decidir la discusión con violencia, hasta que el rey la acalla accediendo al deseo del borgoñón ${ }^{60}$. Ni siquiera en las graves circunstancias de la guerra se toleran las faltas contra las formas. Está universalmente difundida en el mundo anglosajón la anécdota -magistralmente relatada por Shakespeare en su Henry the Fith- de que la entrega al joven rey Enrique de un juego de pelotas de tenis a guisa de presente por un heraldo del delfín de Francia, motivó el desembarco en territorio francés de un ejército inglés y la estrepitosa derrota de las huestes galas

57 Don Álvaro de luna, ejecutado en Valladolid en 1452, fue decapitado en un mezquino cadalso; su cabeza, colocada en un garabato de hierro, estuvo expuesta nueve días, y su cuerpo enterrado de limosna en un cementerio de ajusticiados. Otra célebre ejecución, cuyo recuerdo ha perdurado durante siglos, fue la de Don Rodrigo Calderón, ajusticiado en 1621, que murió con increíble entereza. Su cadáver desnudo, fue depositado en un miserable ataúd sin cubierta, y con orden de que nadie lo acompañara fue enterrado por unos frailes carmelitas [Cfr. CUELLO CALÓN, La moderna penología (Barcelona, 1973) p. 231]. Todavía en el Portugal de Siglo de Las Luces, concretamente en 1758, fueron supliciados y ejecutados los nobles portugueses Marqués de Tavara, sus hijos, su mujer y el Duque de Aveiro, comprometidos en el atentado contra el rey José I [Relación del suplicio recogida de un testigo presencial en GONZÁLEZ NANDÍN, Estudios sobre la pena de muerte (Madrid, 1872) p. 72 ss].

58 Esta disminución del rigor punitivo con los nobles se observa en multitud de pasajes de los autores, bien en enunciados generales o con referencias a casos muy concretos. Por ejemplo, CASTILLO DE BOVADILLA, Política para Corregidores y señores de vasallos II (Amberes, 1750) cap. XIII, núm. 21; ACEVEDO, Consilia Doctoris... post eius obitum perfecta afque congesta per J. Acevedo, authoris filium (Valladolid, 1607) XXIX, fol. 183 vto. A 189 vto., núms. 20 y ss. ("nobilitas minuit poenam ordinariam"); ANTONIO GÓMEZ insiste en que si hay que encarcelar a los nobles ha de ser "in loco honesto et separato, secundum qualitatem personam" [Cfr. Variae resolutiones juris civilis, communis et regii 3 (Madrid, 1780), cap. 3, núm. 2].

59 COVARRUBIAS, Opera omnia II (Salamanca, 1758), cap. IX, p. 210-211.

${ }^{60}$ HUIZINGA, El Otoño, cit., p. 63-64, con abundosa literatura medieval al respecto. 
en la batalla de Azincourt, una de las más sangrientas de la Guerra de los Cien Años ${ }^{61}$. A propósito de este inacabable conflicto bélico, el cronista contemporáneo Froissart nos refiere que un jefe del ejército inglés manda al parlamentario de la asediada Sens que vaya primero a afeitarse ${ }^{62}$.

El 15 de agosto de 1548, a la hora del almuerzo y después de seis meses de ensayo y preparación, fue introducido en la Corte del príncipe Felipe el estilo y uso de la Casa de borgoña; el cambio, no bien recibido por los castellanos ni por las Cortes, había sido ordenado un año antes por el Emperador. Éste, después de su triunfo en Mülhberg de 1547, piensa que ha llegado el momento de presentar a su heredero en los Países Bajos con la pompa vel ostentationem burgundiorum, mucho más rica en magnificencia y esplendor que la sobria y austera castellana ${ }^{63}$. El príncipe Felipe debía pulirse a lo borgoñón para producir inmejorable impresión personal en su recorrido por Flandes. Con ello se reforzó la vigencia del honor caballeresco hasta hacer de los nobles castellanos los europeos más puntillosos y obsesionados por las reglas de distinción personal y precedencia.

Según el ritual impuesto en la corona española por sus ancestros de Bogoña, las etiquetas y ceremonias reguladoras eran estructuralmente necesarias en un grupo de semejantes pero no iguales: diferencias sutiles de forma, estilo, modo, acción, cargo o uniforme debían marcar el rol propio, coeficiente exacto de la especificidad dentro de un espacio común. A ninguno se le puede confundir o amalgamar y, menos que nadie, al rey que todo lo preside desde el puesto culminante de la pirámide jerárquica. Cada uno en su puesto; según su status y situs en la jerarquía palatina, así es acreedor de una exacta correspondencia de la dignidad, privilegio y poder. Toda la vida de la Corte está regida con precisión desde que se levanta el rey hasta que se acuesta. El detalle protocolar dirige la

${ }_{61}$ "Rey Enrique... decid también a ese príncipe placentero, que su burla ha cambiado sus pelotas en piedras de cañón; y que su alma quedará dolorosamente impresionada por la terrible venganza que volará con ellas; porque su burla burlará a buen número de viudas de sus queridos esposos, o madres de sus hijos, a castillos de sus murallas, y todavía están por engendrar y nacer los que tendrán motivo para maldecir el insulto del delfín". [SHAKESPEARE, "La vida del Rey Enrique V", acto I, escena 2a, en Obras Completas ${ }^{15}$, trad. esp. Astrana Marín (Madrid, 1967), p. 522].

62 Cito por la versión española de FROISSART, Crónicas, ed. Cirlot-Ruiz Doménech (Madrid, 1988) p. 121 ss.

63 "El emperador, en un momento cumbre de su política acordó, con el parecer del Duque de Alba ordenar la casa de Felipe al uso de Borgoña". La cita la tomó de DALMIRO DE LA VÁLGOMA, Norma y ceremonia de los reinos de la Casa de Austria (Madrid, 1958) p. 24. Vid., también, PFANDL, "Philipp II und die Einführung der burgundischen Hofzeremoniells in Spanien", en Historisches Jahrbuch 58 (1038). Para LISÓN TOLOSANA, el emperador quizá recordó el humillante ceremonial a que le sometieron en la Seo Zaragozana y la decepcionante impresión que el produjo su llegada a Asturias en 1517, donde desembarcó acompañado de la suntuosa Corte de Borgoña que llenaba cuarenta naves. $L a$ joyeuse entrée se la dieron unos desarrapados lugareños desconfiados que, temiendo lo peor, salieron a defenderse con palos y cuchillos. El elegante cortejo borgoñón encontró la comida detestable, los alojamientos horribles y las comunicaciones pésimas. En cuanto al trato, etiqueta y ceremonial castellanos les parecieron toscos, poco refinados, excesivamente severos y un tanto incultos, como los nobles con los que trataban que ignoraban el francés y el latín [Cfr. La imagen del Rey. Monarquía, realeza y poder ritual en la Casa de los Austrias (Madrid, 1992) p. 115]. 
vida del monarca y la del último pinche de cocina. La ceremonia protocolaria deviene en necesaria, indispensable, inherente a la nobleza que "la ha hech Dios"; el cortesano -dijo Núñez de Castro en frase feliz ${ }^{64}$-debe saber puntualmente "el Levítico [libro bíblico de ritos] de su Príncipe "porque en lo político es la noticia de estas etiquetas, lo que en lo sagrado la de los Preceptos". El noble invitado en especial circunstancia comer con el rey sabe que no puede cubrirse, que debe ocupar una esquina de la mesa y que no pude beber hasta que lo haya hecho su señor.

Cabría traer a colación ad infinitum la casuística de este multisecular puntillismo protocolario, especialmente exacerbado en España durante los tres siglos de dominación de la dinastía habsbúrgica. Simplemente a título ejemplificativo y, a mayor abundamiento, porque tuvo lugar en el Santiago de 1606 entre el arzobispo D. Maximiliano de Austria y la Real Audiencia de Galicia. Conflicto del que nos hemos ocupado en otras sedes ${ }^{65}$ y que -como en su día indicamos- mucho tuvo que ver con la consolidación de A Coruña como capital de la Galicia del Antiguo Régimen ${ }^{66}$. Convenimos con Martínez-Barbeito que si bien en aquel pleito hubo empecinamiento reaccionario por parte de la Audiencia en defender necias prerrogativas protocolarias, desde el punto de vista de sus alegaciones en pro de conservar el "Auto Gallego" como salvaguarda de los derechos de todos frente a los de algunos, tendía a mejorar la administración de justicia y contradecía el mantenimiento de las situaciones privilegiadas ${ }^{67}$.

\section{B) Luis XIV y los Borbones españoles.}

Las ceremonias públicas van a seguir informando de un modo

${ }_{64}$ NÚÑEZ DE CASTRO, Libro histórico politico, sólo Madrid es corte (Madrid, cito por la cuarta reimpresión, 1698) p. 428-429.

${ }^{65}$ Cfr., al respecto, RODRÍGUEZ ENNES, Aproximación a la Historia Jurídica de Galicia (Santiago de Compostela, 1999) p. 81,nt. 172; ID, Historia do Dereito de Galicia (Vigo, 2000) p. 66 ss.

66 Los hechos nos son relatados por LÓPEZ FERREIRO en los siguientes términos:

"Bien es verdad que los Oidores, cuando venían a Santiago, aunque no fuera más que de paso, asientan sus tribunales con alguaciles y escribanos y conocen de todas las causas civiles y criminales, en mucha y en poca cantidad, en primera y segunda instancia contra qualesquiera personas (...) sueltan presos y gobiernan la ciudad como jueces ordinarios y advocan en sí las causas que les parece y usan de la jurisdicción como si fuese suya sin hacer caso de las justicias puestas por el Arzobispo. De tal modo se fue agriando y enzarzando la cuestión que el Arzobispo publicó entredicho en tres leguas alrededor de La Coruña y de Santiago, y excomulgó a los Oidores. A su ve la Audiencia puso Juez en la ciudad de Santiago, desterró al Fiscal de Inmunidades y al Alguacil Mayor y embargó bienes del Arzobispo por valor de mil cuatrocientos ducados. Llegadas las cosas a este punto D. Maximiliano juzgó que estaba en el caso de poner en conocimiento del Rey, todo lo que pasaba, y pedirle personalmente que hiciese justicia. Felipe III, dictó una Real Provisión el 5 de febrero de 1607 en la que ordena a las autoridades eclesiásticas el levantamiento de los entredichos y censuras que hubiesen puesto y absuelven a todos los que por estas causas estuviesen excomulgados libremente y sin costa alguna. Asimismo mandó guardar las leyes acerca del Auto Ordinario de la Audiencia”. [Cfr. Historia de la Santa A. M. Iglesia de Santiago de Compostela, IX (Santiago, 1907) p. 18 ss].

67 MARTÍNEZ BARBEITO El “Auto Gallego", en los tratadistas y en la práctica forense (A Coruña, 1984) p. 29-30. 
peculiar acerca del poder y su imagen durante los siglos finales del Antiguo Régimen. Se trata de festejos que llevan una fuerte carga ejemplificadora y una gran dosis de didactismo, con el fin de proyectar sobre la sociedad un perfil rústico y sin contradicciones del poder y la autoridad. Con el Rey Sol, Luis XIV, introductor de la dinastía borbónica en España, va a alcanzar el cenit de su plasmación el pensamiento maquiavélico de que "el príncipe debe entretener al pueblo en las épocas convenientes, con fiestas y espectáculos (...) teniendo siempre asegurada, no obstante, la magnificencia de su dignidad, porque esto no puede faltar nunca en cosa alguna" ${ }^{68}$.. Razón por la cual -el propio Ludovico Magno, como así se intitulaba -se mostró decidido partidario del ceremonial público y cortesano, en el que veía algo más que meros detalles protocolarios; se trataba del reflejo, expresión y defensa de los privilegios que correspondían a las autoridades y sectores sociales implicados ${ }^{69}$. Voltaire, en su excelente Le Siécle de Louis XIV ${ }^{70}$ nos refiere que "los reyes de Francia querían preceder, por lo menos, a las demás potencias de Europa. Alegaban en su favor el nombre de "muy cristiano". Los reyes de España oponían el título de "católico"; y desde que Carlos Quinto tuvo a un rey de Francia prisionero en Madrid, la soberbia española ni remotamente quería ceder ese rango. Estas pretensiones se debatían antiguamente en Roma. Los papas, que daban los estados por una bula, se creían con mayor razón, en el derecho de decidir el rango entre las coronas. Esta corte a lo que todo se le va en ceremonias, eran el tribunal donde se juzgaban esas vanidades de la grandeza.

La disputa entre Francia y España estaba indecisa: un paso de más o de menos en una procesión, un sillón colocado cerca de un altar, o frente al púlpito de un predicador, eran triunfos y establecían títulos para la preexistencia.

El puntillo de honor se extremaba entonces a éste respecto entre las coronas, como el furor de los duelos entre los particulares. Ocurrió -sigue escribiendo el más egregio de los ilustrados- que en 1661 al entrar en Londres un embajador de Suecia, el conde de Estrades, embajador de Francia, y el barón de Vatteville, embajador de España, se disputaron el paso. El español, con más dinero y con séquito más numeroso, se ganó al populacho inglés: primero hizo matar los caballos de las carrozas francesas y luego la gente del conde de Estrades, herida y dispersada, dejó marchar en son de triunfo a los españoles. En 1662, Luis XIV, informado del insulto, llamó a su embajador en Madrid, hizo salir de Francia al de España, anuló las conferencias que se realizaban todavía en Flandes con motivo de los límites, y comunicó a su suegro -y tío- Felipe IV, que si no reconocía la superioridad de la corona de Francia y no reparaba la afrenta con una satisfacción solemne, volvería a empezar la guerra. Felipe IV no quiso hundir a su reino en una

68 MAQUiaVelo, El Príncipe, ed. Martínez Aragón (Madrid, 1988) p. 95. Más información en SANTAELLA LÓPEZ, Opinión pública e imagen política en Maquiavelo (Madrid, 1990).

${ }^{69}$ LUIS XIV, Memorias, cit. por ELÍAS, La sociedad cortesana (México, 1982) p. 160.

${ }^{70}$ Cito por la traducción española de Nélida Orfila (México, 1954) p. 74 ss. 
nueva guerra por la precedencia de un embajador, y envió el conde de Fuentes a declara al rey, en Fontaineblau, en presencia de todos los ministros extranjeros que estaban en Francia, "que los ministros españoles no concurrirán en adelante con los de Francia”. A partir de entonces, Luis XIV adquirió con su firmeza, una superioridad real en Europa e hizo ver cuán terrible era"71.

Constituía lugar común en el siglo XVIII observar que el fasto tenía una función política. Daba éclat al rey. Éclat era otra palabra clave de la época, con significados que iban desde el "relámpago" al "trueno", pero siempre refiriéndose a algo inesperado e impresionante. El fasto se consideraba impresionante, en el sentido literal de que dejaba una "impresión" en los espectadores como un sello en un pedazo de cera. En este sentido, Colbert decía del palacio del Louvre que imprimía respeto en los pueblos del mundo ${ }^{72}$. El propio Luis explicaba al Delfín que los festivales gustaban a los súbditos y daban a los extranjeros "una impresión muy útil de magnificencia, poder, riqueza y grandeza"73. Bossuet usaba palabras análogas cuando en su tratado sobre política, señalaba que la corte de un monarca es "deslumbradora y magnífica" -éclatante et magnifique- para que los pueblos lo respeten ${ }^{74}$. Un teórico social como Montesquieu, que se crió en el reinado de Luis XIV, afirmaba algo parecido: "El fasto y esplendor que rodean a los reyes forman parte de su poder"75. Resulta tentador ir más lejos y hablar del "Estado espectáculo" el Rey Sol. La frase -aunque de progenie moderna ${ }^{76}$-habría gustado sin duda a los contemporáneos de Luis XIV, que estaban acostumbrados a ver el mundo como un escenario. Luis mismo utilizó la metáfora alguna vez ${ }^{77}$. El Duque de Saint-Simon, quizás el más conspicuo memorialista del reinado, usó constantemente términos como comédie y scéne en sus descripciones de la corte ${ }^{78}$. Más de uno de los sermones pronunciados con ocasión de la muerte del rey se refirieron a su vida como un gran "espectáculo"79.

71 Ibid., p. 75-76.

72 "Toute la structure imprime le respect dans l'esprit des peuples" [Cfr. Clément (ed.) Lettres, instructions et mémoires de Colbert, 5 vols (París, 1868) tomo 5, p. 246]. La referencia es probablemente a los pueblos de Europa, y no sólo al francés.

73 "Une impresión trés avantagense de magnificence, de puissance, de richesse et de grandeur" [Cfr. Longnon (ed.) Louis XIV, Memoires (París, 1927, reimpr. 1983) p. 22 ss.

74 "Pour imprimer aux peuples un certain respect". [Cfr. BOSSUET, Oraisons funébres (ed. Trouchet) (París, 1967), libro 10].

75 "Le faste et le splendeur qui environnent les rois front une partie de leur puissance". [Cfr. MONTESQUIEU, Oeuvres (París, 1973) p. 58].

76 El concepto de "Estado espectáculo" fue propuesto hace unos veinte años por el antropólogo norteamericano GEERTZ en su influyente estudio sobre el Bali decimonónico Negara: The Theater State in Nineteenth-Century Bali (Princeton, 1980).

77 La primera vez que vio a la Duquesa de Borgoña -que a la sazón tenía once años- Luis comentó a Madame de Maintenon que cuando le llegara el tiempo de representar su papel en el escenario de la corte, lo haría con gracia y encanto ["Quand il faudra un jour qu'elle répresente, elle sera d'un air et d'une grace á charner". Cfr. Gaxotte (ed.) Lettres de Louis XIV (París, 1930) p. 104].

78 SAINT-SIMON, Memoires, (ed. Y. Couriralt) 8 vols. (París, 1983-1988) vol. I p. 714, 781 y 857.

79 KERTZER, Ritual, Politics and Power (New Haven-Londres, 1988). 
El ritual, especialmente, se veía como una especie de drama que tenía que escenificarse para fomentar la obediencia. Un estudioso alemán Lüning, que publicó un análisis general sobre las ceremonias públicas en 1719-1720, lo 1lamó Theatrum Ceremoniale y explicó que este tipo de teatro era necesario porque "entre la gente corriente... las impresiones físicas tienen un efecto mayor que el lenguaje que se dirije al intelecto y la razón" $"$. En las memorias de Luis se sostiene algo parecido ${ }^{81}$. Los análisis de la importancia del ritual en la política contemporánea se basan en supuestos análogos. Esta proyección se plasma en la presentación de unos valores que dignifican, ensalzan y engrandecen a la monarquía y al rey en primer lugar, a las autoridades eclesiásticas y a los poderes e instituciones civiles. Esta acción propagandística de las ceremonias públicas se apuntala-sobre todo en épocas turbulentas- con la presentación de aquellos contravalores que ponían en entredicho los fundamentos del sistema político y social; así, frente al Orden se contrapone el Desorden frente a la justicia la Arbitrariedad, frente a la Ortodoxia la Heterodoxia. Claro está que lo que sea cada uno de estos valores y contravalores, depende de quien organice las ceremonias en cada caso.

Las ceremonias muestran junto a la imagen del poder, la de una estructura social. Las pautas por las que se rigen -apreciables en las normas y costumbres ceremoniales y protocolarias- expresan formas específicas de encuadramiento vecinal y de jerarquización institucional. En cierta manera, las ceremonias exteriorizan el modo en que se consideraba que debía organizarse la sociedad y cuáles debían ser los principios de tal organización. Se presentan así como un vehículo para la defensa de una serie de principios de carácter político y social, a los que también habría que añadir otros de perfil religioso e ideológico íntimamente asociados a los anteriores. Los ceremoniales y los protocolos de los desfiles procesionales, de las funciones cívicas y religiosas, no son en absoluto intrascendentes bajo esta perspectiva; obedecen a una graduación y jerarquización de la sociedad y de sus miembros, en conformidad con los criterios de la época ${ }^{82}$.

El modelo de la sociedad cortesana de Luis XIV puede resultar útil para la interpretación de las ceremonias del Antiguo Régimen ya que, con las debidas cautelas, aporta una serie de consideraciones que pueden trasladarse a los comportamientos y actitudes de las instituciones urbanas, de manera que las ceremonias y celebraciones públicas adquieren un sentido y un valor más profundo que la simple formalidad o aparato externo. La atención y el cuidado con que se preparaban las ceremonias y los pleitos que por su causa de suscitaban,

${ }^{80}$ LÜNIG, Theatrum Ceremoniale Historicum Politicum, 2 vols., (Leipzig, 1719-1720).

${ }^{81}$ LONGNON, Memoires, cit.

82 ROBERTO J. LÓPEZ, Ceremonia y poder a finales del Antiguo Régimen. Galicia 1700-1833 (Santiago, 1955) p. 14 ss. 
deben entenderse con un modelo de autopresentación de las instituciones urbanas que se ejercían algún tipo de poder; una autopresentación en la que la opinión del pueblo y de las demás instituciones desempeñaba un papel determinante, el poder y el prestigio de cada una dependía, no sólo de su capacidad objetiva de decisión, sino del refrendo del resto del cuerpo social ${ }^{83}$.

\section{C) La Galicia del Antiguo Régimen.}

Por lo que hace a Galicia, la similitud formal de nuestras ceremonias con las de otros lugares próximos a la Corte, puede servir de argumento para afirmar la progresión del proceso de centralización del poder en el Antiguo Régimen o, lo que es lo mismo, del avance y consolidación del llamado Estado Moderno ${ }^{84}$. No obstante, tal avance se produjo en medio de las tensiones y las paradojas derivadas del mantenimiento de jurisdicciones menores, de privilegios y exenciones que en la práctica hacen del pretendido centralismo, incluso en el siglo XVIII, una referencia más nominal que real. Los roces y los enfrentamientos que se originaron en la organización y desarrollo de las ceremonias públicas son un reflejo de tales paradojas; los diferentes protagonistas no parecen haber tenido ninguna dificultad para aunar esfuerzos y apoyar al monarca, pero no suelen mostrarse dispuestos a renunciar a sus prerrogativas y derechos, y tratarán de utilizar también en provecho propio las celebraciones públicas.

La organización y presencia en las ceremonias públicas son una ocasión que aprovechan las instituciones urbanas para destacarse ante las demás y los que asisten a los actos: "Conventos, parroquias, gremios y colegios, nobleza y cabildo, compiten en alcanzar el mayor lucimiento, con un orgullo corporacional que les enfrenta apasionadamente rompiendo la desidia y dejación cotidiana"; estas luminosas palabras escritas por Mínguez Cornelles a propósito de los festejos valencianos dieciochescos son plenamente trasladables a la Galicia del período ${ }^{85}$.

83 ELÍAS, La sociedad cortesana, cit., deben consultarse especialmente los capítulos V ("Etiqueta y ceremonial: conducta y mentalidad de hombres como funciones de la estructura de poder de su sociedad", p. 107-158) y VI ("La vinculación del rey por la etiqueta y las oportunidades de prestigio" p. 159-196). Un breve comentario de éste y otros trabajos sobre la materia, y de su situación en el contexto historiográfico, puede encontrarse en MOZZARELLI, "Príncipe e Corte. Porqué e cómo estudar, hoje, a Corte?", en Penélope 9-10 (1993) p. 225-229.

84 La bibliografía sobre el Estado Moderno es muy abundante y las diferencias entre los autores a veces abismales. A título únicamente indicativo, citamos los siguientes trabajos. CLAVERO, "Institución política y Derecho: acerca del concepto historiográfico de Estado Moderno", en Revista de Estudios Políticos 19 (1981) p. 43-57; ID., Tantas personas como estados (Madrid, 1986); FERNÁNDEZ ALBADALEJO, Fragmentos de monarquía (Madrid, 1992); GONZÁLEZ ALONSO, "Del Estado absoluto al Estado constitucional", en Manuscrits 4-5 (1987) p. 81-90.

85 MÍNGUEZ CORNELLES, "El festejo valenciano dieciochesco: arquitecturas, esculturas y decorados efímeros”, en Saitabi 37 (1987) p. 256. 
Esta pugna se refleja en el ámbito universitario ${ }^{86}$ y de un modo bastante claro en el relato de la aclamación de Fernando VII en Lugo, en particular entre los gremios:

\author{
Estas danzas las disponen \\ de la ciudad quatro gremios \\ y cada cual procuraba \\ ser en todos aliños el primero \\ Con que ya colegirán \\ yendo cada cual a empeño \\ que en competencia sería \\ el lucir primoroso y con excesos ${ }^{87}$
}

De la emulación es fácil pasar a la desconfianza y al enfrentamiento. Las causas que desencadenan estos conflictos son muy variadas, pero pueden resumirse en dos: las derivadas de la organización y desarrollo de las ceremonias y las derivadas del protocolo. Tanto en un caso como en otro, se trata de dejar claro el valor, derechos y preeminencias de la institución que se siente afectada ante la que se presume que es la ofensora, bien porque se extralimita en sus atribuciones inadvertidamente, o porque se piensa que actúa así de modo deliberado ${ }^{88}$. Lo que se disputa en estos casos no es sólo una cuestión formal sino, sobre todo, una cuestión de poder y autoridad. Aquí radica la explicación de la gran disputa que en 1674 se entabló entre el Cabildo compostelano y la Real Audiencia, ocasionada

86 La rivalidad amistosa parece ser la tónica dominante, por ejemplo, en la presentación y participación de la universidad y los colegios de Fonseca y San Clemente en los festejos por el embarazo de la reina María Luisa de Saboya: "No ha avido comunidad que no alentase el gozo en demostraciones siendo una de ellas la ilustre Universidad, Athenas numerosa de sabios, florido circo de ingenios, girasol tan del gusto de su monarca (...), contribuyendo amante rendidas sus opulencias. Emuláronse los dos Colegios aerópagos ilustres, en donde se crian sus hijos para oráculos. Uno fundación del gran Fonseca, príncipe excelso, que selló nuestros corazones con beneficios, y quien en estatuas de su grandeza, tiene en eterna veneración nuestra memoria. Y el otro edificio sumptuoso de el Ilustrísimo Señor Don Juan de San Clemente Torquemada, entonces vivo prodigio, y aora muerto admiración de las edades" [Cfr. Gratitud sacra y festiva... en la ... ciudad de Santiago por la feliz noticia del preñado de la Reyna nuestra señora $D^{a}$ María Luisa Gabriela de Saboya (Santiago, 1707) p. 8-9].

87 Relación de las festivas demonstraciones que la... ciudad de Lugo... expresó sus júbilos en la aclamación...de...el señor Don Fernando VII (Santiago, 1746) p. 3.

88 Vale para el caso de explicación que ELÍAS da de la importancia del ceremonial en la sociedad cortesana, aplicando a las instituciones urbanas lo que se dice de los cortesanos. Para éstos, los detalles de la etiqueta "no constituían en absoluto nimiedades, sino identificaciones directas de la existencia social, a saber del lugar que uno ocupaba efectivamente en la jerarquía de la sociedad cortesana. Subir o bajar en esta jerarquía significaba para los cortesanos -tanto como para el comerciante- ganancias o pérdidas en su negocio. Y la irritación de un cortesano ante la amenaza de ruina de su rango y su prestigio no era menor que la del comerciante ante la amenaza de perder su capital, o de un gerente o un funcionario ante la amenaza de perder las oportunidades de hacer carrera" (Cfr. La sociedad cortesana, cit., p. 128). 
porque los canónigos colocaron una corona en el túmulo levantado en las exequias del Conde de Lemos, Virrey del Perú, la Audiencia interpretó como corona real y, por tanto, fuera de lugar ${ }^{89}$. Otra muestra más de hasta qué extremos de radicalismo podía conducir el descuido de algún nimio detalle lo tenemos en la polémica que a finales de 1703 se entabla entre el Cabildo catedralicio compostelano -siempre ojo avizor en la defensa de su status privilegiado- y el Capitán General de Galicia, el Duque de Híjar, con ocasión de su visita a Santiago. El Cabildo envió a unos comisarios para que le saluden en su nombre, y se encontraron con que el Capitán General no salió a recibirles a la puerta, ni les preparó las sillas, tampoco dio el tratamiento requerido y no tuvo la delicadeza de acompañarles hasta la salida cuando se despidieron. Ante lo que el Cabildo consideró un atropello de su dignidad y autoridad y tomó el acuerdo de:

Que ningún señor capitular so pena de 200 ducados visitase ni cortexase a su S. E., ni al entrar en la yglesia se le sirviese el agua bendita, ni tocaren órganos ni chirimías, ni se le previniese tapete ni almohada, ni se le hiziesen los demás obsequios que se acostumbran a los señores Capitanes Generales y Grandes de España quando entan como particulares en la yglesia, hasta que diese al Cavildo la estimación que siempre ha gozado ${ }^{90}$.

Ni que decir tiene que las explicaciones y satisfacciones que se exigían fueron puntualmente presentadas. Si esto sucedía en una simple visita protocolaria, no resultará extraño que a lo largo de todo el Antiguo Régimen, las discusiones menudeasen en las ceremonias públicas; las ocasiones y motivos se multiplicaban al multiplicarse los componentes y minucias del protocolo.

\footnotetext{
89 ACS, leg. 357, "1674 Honras por el Conde de Lemos, Virrey del Perú. Autos de la Audiencia de Galicia...".

90 ACS, leg. 359, hoja suelta.
} 